\title{
The Flight of the Unicorns, by Anthony Shepherd. Elek Books, $30 \mathrm{~s}$
}

This intriguing title conceals the identity of the remarkable expedition, of which the author was a prominent member, promoted by the Fauna Preservation Society in a desperate endeavour to capture a few of the remaining Arabian ory $x-$ one of the rarest and most graceful of the world's mammals - in order to establish in captivity the nucleus of a breeding herd. The mechanical age has enabled regions hitherto inaccessible to the hunter to be penetrated by fast motorcars whose occupants, using firearms of precision, have indulged in orgies of mass slaughter until perhaps no more than two hundred oryx remain in the wild state, the majority to some extent protected by the sanctuary of the "Empty Quarter" of ill-fame. On the other hand, without the motorcar the expedition would have failed.

It is a thrilling account of an astonishing combined operation, and above all of cheerful companionship and co-operation; but for the generous help of a host of well-wishers, Arab and Briton alike, representing many spheres of activity, the best laid plans would have come to naught. The actual catching of the fabulous unicorn is told briefly in three chapters, and it is clear that had there been more time at the expedition's disposal better results would have been assured-for an oryx had only to be viewed for it to be quickly in the bag. However, two males and one female oryx were caught and eventually taken to a zoo in Arizona to form the nucleus of a herd that is now breeding - four calves born and more expected-so the results of the expedition have proved more successful than perhaps seemed likely at the time. It was a tough assignment carried out over most difficult terrain and in appalling conditions of blistering heat, together with the need for ever increasing improvisation, and its successful conclusion was little short of miraculous. One marvels at the fortitude of the leader who carried on, gallantly and albeit painfully, with broken ribs at the most critical period of the operation, as well as at the skilful use of a light aircraft brought from Kenya which, scorning the hazards of the absence of maintained airstrips, never went wrong-indeed an impressive performance.

The author traces the history of the Arabian oryx over the past 450 years, with much of interest about the Arabs' mode of life, and there are useful appendices, including lists of birds-a pity scientific names were not checked for typographical errors-and of the vegetation and plants eaten by the oryx, and the plants collected; also a short bibliography. Pleasingly illustrated, it makes fascinating, rewarding reading and can be thoroughly recommended.

\section{R. S. PITMAN.}

\section{Portrait of a Desert, by Guy Mountfort. Collins, 36s.}

Nine-tenths of Jordan is a wilderness inhabited by nomadic Beduin tribes, a remote area of great scenic beauty still redolent of the exploits of Lawrence of Arabia, but of particular scentific interest and offering unusual opportunities for investigations into problems of the ecology and conservation of desert and semi-desert areas. This book is the story of the 1963 scientific expedition to Jordan undertaken at the request of King Hussein, told by the skilful organiser and leader in the third of his admirable "Portrait" series; his characteristic discourse is simple, factulal and informative. The king's enthusiastic support ensured the whole-hearted co-operation of his Beduin subjects, without which little would have been accomplished.

Goats in Jordan, as in many parts of the world, are an unmitigated plague, but other factors contribute to the ceaseless, progressive destruction of the vegetation: "a quarter of an acre of the sparse desert shrublets disappears every time the Beduin brews a pot of coffee". Basically the 